\title{
Association between specific dystrophin gene mutations and myocardial fibrosis by cardiovascular magnetic resonance imaging in patients with Duchenne and Becker muscular dystrophy
}

\author{
Marly C Silva ${ }^{1,4^{*}}$, Carlos H Rassi', Zilda M Meira², Juliana G Giannetti ${ }^{2}$, Mariz Vainzof ${ }^{3}$, Mayana Zatz ${ }^{3}$, Roberto Kalil', \\ Carlos E Rochitte ${ }^{1}$
}

From 17th Annual SCMR Scientific Sessions

New Orleans, LA, USA. 16-19 January 2014

\section{Background}

Duchenne (DMD) and Becker (BMD) muscular dystrophies (MD) are allelic X-linked recessive disorders, caused by mutation of the dystrophin gene located at locus Xp21 that consists of 79 exons, characterized by progressive skeletal muscle degeneration and replacement by fibro fatty tissue. Dystrophin is a sarcolemal protein that links the cytoskeleton to the basal lamina and is essential for maintenance of the muscular membrane integrity during muscular contraction. Cardiac involvement is frequent, $70-80 \%$ of patients, and often develops clinically silent, without any evident early clinical signs. CMR can identify myocardial fibrosis (MF) and may be useful for detecting the early stages of cardiomyopathy in MD. In a previous study, DNA analyses in 47 pts with DMD revealed significant association between dilated cardiomyopathy (DCM) and specific exons and possible protection against DCM by other exons. The association between specific exons mutation of the dystrophin gene and myocardial fibrosis is until unknown.

\section{Methods}

We enrolled 76 pts, 70 pts DMD and 6 BMD with confirmed muscular dystrophy. Mean age was $13.1 \pm 4.4$ years. MLPA tests were performed on all these patients.

${ }^{1}$ Cardiology, Heart Institute, InCor, University of São Paulo Medical School, São Paulo, São Paulo, Brazil

Full list of author information is available at the end of the article
40 pts showed DNA mutation. According to specific exons mutation, these patients were classified into 2 groups: with exons mutation below 45 and with mutation on or above 45. All patients underwent CMR study in a 1.5-T Siemens Avanto (Erlangen, Germany), using cine resonance for function evaluation and myocardial delayed enhancement (MDE) technique for myocardial fibrosis detection, $10 \mathrm{~min}$ after intravenous bolus of 0.2 $\mathrm{mmol} / \mathrm{kg}$ of gadolinium-based contrast. Cine and MDE parameters were, respectively: TR 2.0/9.0, TE 1.07/5.0; FA 69/50; cardiac phases 20/1; VPS $8 / 16$ to 32 ; matrix $192 \times 162 / 256 \times 192$; ST $8 / 8 \mathrm{~mm}$; gap $2 / 2$ and FOV 3238/32-38 cm; TI none/150-390 ms. Two experienced observers measured LV volumes and ejection fraction by the Simpson method (Argus software, Siemens). In the MDE short axis images, we evaluated the MF mass per patient, using a 5 standard deviation thresholding technique, on CMR42 software, version 3.4.2 (Circle Cardiovascular Imaging, Calgary, Alberta, Canada). Mann Whitney was used for comparison of myocardial fibrosis between the group with mutation in exons $<45$ and mutation in exons $\geq 45$.

\section{Results}

Of the 40 pts with DNA mutation, 16 pts showed mutation below exon 45 and 25 pts in exons on or above 45 . The specific mutations were shown to be associated with cardiac involvement (myocardial fibrosis). Patients with mutations in exons less than 45 had greater extent of 


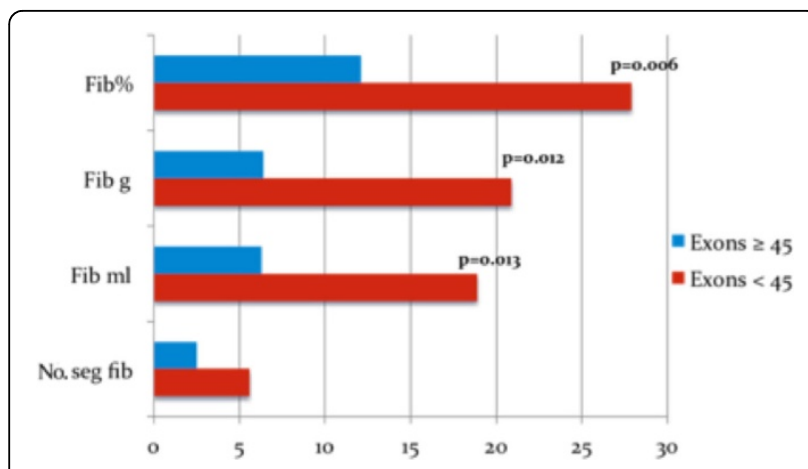

Figure 1 Myocardial fibrosis quantification in DMD and BMD patients with mutation in exons $\geq \mathbf{4 5}$ and $<\mathbf{4 5}$. Fib\% -

myocardial fibrosis as percent of LV mass Fib $\mathrm{g}$ - myocardial fibrosis in grams Fib $\mathrm{ml}$ - myocardial fibrosis volume in milliliters No. seg. fib - number of AHA segments with fibrosis.

myocardial fibrosis than patients with mutations in exons greater than or equal to 45 in CMR at baseline $(27.9 \pm$ $18.4 \%$ vs. $12.1 \pm 13.4 \%$, respectively, $\mathrm{p}=0.006)$ and at follow-up $(33.1 \pm 21.1 \%$ vs. $18.8 \pm 16.9 \%$, respectively, $\mathrm{p}=$ 0.024).

\section{Conclusions}

There was a significant correlation between the site of mutation in the dystrophin gene and myocardial fibrosis. Mutations in exon $\geq 45$ appear to protect against cardiac involvement.

\section{Funding}

No funding.

\section{Authors' details}

${ }^{1}$ Cardiology, Heart Institute, InCor, University of São Paulo Medical School, São Paulo, São Paulo, Brazil. ${ }^{2}$ Cardiology and Pediatry, Federal University of Minas Gerais, Belo Horizonte, Minas Gerais, Brazil. ${ }^{3}$ Human Genome Research Center, Bioscience Institute, University of São Paulo, São Paulo, São Paulo, Brazil. ${ }^{4}$ Radiology, Axial Centro de Imagem, Belo Horizonte, Minas Gerais, Brazil.

Published: 16 January 2014

doi:10.1186/1532-429X-16-S1-P325

Cite this article as: Silva et al:: Association between specific dystrophin gene mutations and myocardial fibrosis by cardiovascular magnetic resonance imaging in patients with Duchenne and Becker muscular dystrophy. Journal of Cardiovascular Magnetic Resonance 2014 16(Suppl 1): P325.

\section{Submit your next manuscript to BioMed Central} and take full advantage of:

- Convenient online submission

- Thorough peer review

- No space constraints or color figure charges

- Immediate publication on acceptance

- Inclusion in PubMed, CAS, Scopus and Google Scholar

- Research which is freely available for redistribution

Submit your manuscript at www.biomedcentral.com/submit
C BioMed Central 